\title{
REAPOWER - USE OF DESALINATION BRINE FOR POWER PRODUCTION THROUGH REVERSE ELECTRODIALYSIS
}

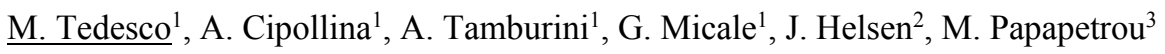 \\ ${ }^{1}$ Dipartimento di Ingegneria Chimica, Gestionale, Informatica, Meccanica (DICGIM), Università di Palermo \\ (UNIPA) - viale delle Scienze Ed.6, 90128 Palermo, Italy. \\ ${ }^{2}$ VITO (Flemish Institute for Technological Research), Unit Separation and Conversion Technology, Boeretang \\ 200, B-2400, Mol, Belgium \\ ${ }^{3}$ Wirtschaft und Infrastruktur GmbH \& Co Planungs-KG (WIP), Sylvensteinstr. 2, 81369, Munich, Germany
}

Presenting author's contact details:

email: michele.tedesco@unipa.it

phone: +3909123863780 / fax: +3909123860841

mobile: +393291439134

\begin{abstract}
Salinity Gradient Power (SGP) represents a viable renewable energy source associated with the mixing of two solutions of different salinities. Reverse Electrodialysis (SGP-RE) is, in turn, a promising technology to exploit this energy source and directly generate electricity. However, although the principle of this technology is well known since several years, further $R \& D$ efforts are still necessary in order to explore the real potential of the SGP-RE process. With this regard, the aim of the REAPower project (www.reapower.eu) is the development of an innovative system for power production by SGP-RE process, using seawater as dilute solution and brine as concentrate. The use of seawater (instead of fresh water) as diluate allows reducing the electrical resistance of the diluate compartment, increasing the achievable output power.

This work presents the R\&D activities carried out so far within the REApower project, particularly focusing on the relevant progresses in membranes development, stack design and process modelling. An extensive experimental campaign has been performed on a lab-scale unit, allowing to reach the highest power density so far presented in the open literature.

These results provided useful information for the final goal of the project, i.e. the construction of the first SGPRE system on a small pilot-scale, in order to demonstrate the feasibility of the future scale-up for this technology.
\end{abstract}

\section{Keywords}

Salinity Gradient Power, Reverse Electrodialysis; ion-exchange membrane; modelling; seawater; brine. 


\section{Introduction}

Salinity Gradient Power (SGP) is the chemical energy available from the controlled mixing of two aqueous solutions with different salt concentrations. The global potential is high as solutions with different salinities in close proximity occur frequently in nature, like for example where the rivers meet the sea. Up to now, three different technologies have been proposed in the literature for collecting this energy source: Reverse Electrodialysis (RE or RED) [1, 2], Pressure Retarded Osmosis (PRO) [3] and Capacitive Double Layer Expansion (CDLE) [4]. Reverse Electrodialysis (SGP-RE) allows the direct conversion of SGP into electric power by means of suitable ion exchange membranes (IEMs), and can be addressed as a truly promising technology [5].

A SGP-RE unit is essentially constituted by Cation/Anion Exchange Membranes (CEM/AEM) alternatively piled into a stack. The principle of SGP-RE process can be summarised as follows: when two salt solutions are fed to the stack, the concentration gradient between them forces the ions to move through the membranes. This ion flux is regulated by ions mobility and membrane permselectivity, i.e. the selectivity towards cation/anion transport through CEM/AEM, respectively. Finally, this ionic current through membranes is converted into electric current by means of redox reactions at the electrodes, positioned at the two ends of the stack, and can be collected by an external load.

The amount of electric power being collected from a SGP-RE unit depends on several factors, such as membranes properties, stack design, concentration of solutions., etc. For instance, it is worth noting that the use of fresh water as dilute solution provokes high electrical resistance inside the stack, limiting the output power. A possible way to avoid this high resistance in the diluate compartment is using seawater (instead of river water) as dilute, and a more concentrated solution as concentrate, such as concentrated brine from saltworks, salt mines or other industrial activities [6]. This is the main idea behind the REAPower project, as will be explained in the next paragraph.

\subsection{The REAPower project}

The aim of the REAPower project (Reverse Electrodialysis Alternative Power [7]) is the power production by SGP-RE technology using seawater and brine as feed solutions. The use of seawater as diluate and concentrated brine as concentrate allows to significantly reduce the internal electrical resistance of the SGP-RE stack, therefore increasing the power output. On the other hand, the presence of highly concentrated solutions inside the system strongly affects membrane properties, especially permselectivity. As a consequence, further R\&D efforts are still necessary in order to eventually enhance the process performance.

For this reason, the following R\&D activities have been identified and addressed within the REAPower project:

i. To identify and if necessary create new materials and components tailored to the process requirements, such as membranes, spacers, electrodes and redox species;

ii. To optimise the design of the SGP-RE system by means of advanced computer-aided process design tools;

iii. To verify the model, and assess the developed materials, components and design through tests on laboratory stacks;

iv. To test the SGP-RE system on a prototype fed with real solutions (i.e. seawater and brine from a salt works);

v. To analyse both economic and environmental impact, as well as define the next necessary R\&D activities for further development of the technology.

An important goal to be achieved by the end of the project-life (Sept 2014) is the installation of a demonstration prototype plant in the South of Italy. The installation site is located close to traditional saltworks, a truly suitable area for a SGP-RE plant thanks to the availability of both seawater and concentrate brines from evaporating basins [6]. 


\section{Project achievements}

This section summarises the most relevant results achieved for enhancing the performance of SGP-RE. Most of these results have been presented in more specific literature works, which will be referenced for any further details. The main efforts have been focused on the following issues:

- development of new ion exchange membranes suitable for highly concentrated solutions;

- selection of the best conditions for the electrode compartments as well as for flow distribution inside the stack;

- experimental investigation on the newly developed lab-scale stack;

- development and validation of a predictive modelling tool for the SGP-RE process.

- Use of the modelling tool for the design of the SGP-RE prototype and relevant perspectives analysis.

\subsection{Improvements in membranes development}

The overall performance of the SGP-RE process is strongly dependant on the membranes' properties, especially permselectivity and electrical resistance. This is particularly significant when using seawater and brine as feed solutions, where the IEMs' resistance are the controlling resistance of the stack thanks to the high conductivity of the diluate compartment [8]. Moreover, the use of highly concentrated solutions (e.g. 4-5 M NaCl, i.e. almost saturated brines) significantly reduces the permselectivity of standard IEM to values of about $50 \%$ [9]. With this regard, Fujifilm has developed a new recipe for IEMs, allowing to reach a permselectivity of $65 \%$ for AEM and up to $90 \%$ for CEM using $0.5 \mathrm{M} \mathrm{NaCl}$ and $4 \mathrm{M} \mathrm{NaCl}$ as feed solutions.

\subsection{Selection of the best conditions for the electrode compartments and manufacturing of a newly designed stack}

The possible redox reactions involved in the SGP-RE process can have a role of paramount importance in controlling the performance of a stack, especially when a limited number of cell pairs is adopted [10-13]. Within the REAPower project these conditions have been widely investigated both in terms of suitable redox couple and electrode materials, with specific regard to the case of using highly concentrated solutions for feeding the stack $[10,11]$. Among the possible redox couples which could be used for the SPG-RE process, the following species were chosen for a detailed experimental investigation: $\mathrm{FeCl}_{3} / \mathrm{FeCl}_{2}, \mathrm{~K}_{3} \mathrm{Fe}(\mathrm{CN})_{6} / \mathrm{K}_{4} \mathrm{Fe}(\mathrm{CN})_{6}$ and $\mathrm{Fe}(\mathrm{III})-$ EDTA/Fe(II)-EDTA. These species were selected on the basis of their rather high stability, combined to low toxicity and high solubility in water. The experimental study was performed both on graphite and DSA electrodes [10].

Finally, the most promising species identified for the SGP-RE process were $\mathrm{FeCl}_{3} / \mathrm{FeCl}_{2}$ and $\mathrm{K}_{3} \mathrm{Fe}(\mathrm{CN})_{6} / \mathrm{K}_{4} \mathrm{Fe}(\mathrm{CN})_{6}$. In particular, the $\mathrm{K}_{3} \mathrm{Fe}(\mathrm{CN})_{6} / \mathrm{K}_{4} \mathrm{Fe}(\mathrm{CN})_{6}$ couple showed a quite high stability (i.e. no significant change in composition after 12 days of electrolyses measurements [10]). However, this long term stability is guaranteed only avoiding the presence of light and oxygen inside the electrode compartments. The $\mathrm{FeCl}_{3} / \mathrm{FeCl}_{2}$ couple, on the other hand, has a comparable stability provided that the $\mathrm{pH}$ inside the electrode compartments is kept low $(\mathrm{pH}<3)$. This is necessary in order to prevent the precipitation of ferric oxyhydroxides .

Regarding the stack design itself, a new cross-flow configuration has been purposely designed and built by REDSTACK B. V. aiming at ensuring a better flow distribution and lower pressure drops inside channels. Moreover, in this unit, a more uniform current distribution is guaranteed through the stack, allowing to reduce the internal electrical resistance and, therefore, increase the output power achievable.

\subsection{Experimental investigation on a lab-scale unit}

An extensive experimental campaign has been carried out at VITO using a lab-scale SGP-RE unit with 10x10 $\mathrm{cm}^{2}$ membrane area and 50 cell pairs. The aim of this experimental study was the characterisation of the SGP- 
RE system performance under a wide range of operating conditions. In particular, the following operating variables have been taken into account $[14,15]$ :

- $\quad$ feed flow velocity inside channels $(0.1-4 \mathrm{~cm} / \mathrm{s})$;

- $\quad$ solutions temperature $\left(20-40^{\circ} \mathrm{C}\right)$;

- $\quad$ number of cell pairs $(5-50)$;

- $\quad$ concentration of redox couple $\left(0.1-0.3 \mathrm{M}\right.$ of $\left.\mathrm{K}_{3} \mathrm{Fe}(\mathrm{CN})_{6} / \mathrm{K}_{4} \mathrm{Fe}(\mathrm{CN})_{6}\right)$;

- $\quad$ salt concentration of both solutions $(0.1-1 \mathrm{M}$ of $\mathrm{NaCl}$ for diluate, $0.5-5 \mathrm{M}$ of $\mathrm{NaCl}$ for concentrate).

All the measurements were performed using demineralised water and technical grade $\mathrm{NaCl}$ (Frisia Salt, The Netherlands) for the artificial salt solutions. A "reference condition" has been defined for all tests using $0.5 \mathrm{M}$ $\mathrm{NaCl}$ solution ad diluate and $5 \mathrm{M} \mathrm{NaCl}$ solution as concentrate at $20^{\circ} \mathrm{C}$.

For the sake of brevity, only the major dependences are reported here (further details can be found in the relevant literature references), relevant to the variation of fluid velocity, feed temperature and concentration. Figure 1.a shows how the increase in fluid velocity inside the channels slightly increases the obtained power density, achieving a plateaux after $1 \mathrm{~cm} / \mathrm{s}$. However, the relevant increase in pumping power leads to a dramatic reduction of the net maximum power density (i.e. the power density reduced by the amount of pumping power consumed), indicating that, under the analysed experimental conditions, a fluid velocity between $0.5 \mathrm{and} 1 \mathrm{~cm} / \mathrm{s}$ is recommended for optimal net power output.

Interestingly, Fig. $1 \mathrm{~b}$ shows how an increase in feed temperature from 20 to $40^{\circ} \mathrm{C}$ leads to an increase of power output by about $50 \%$. This is due to a small increase in the cell pair electromotive force and, more importantly, to a significant reduction in the stack resistance with higher temperatures.

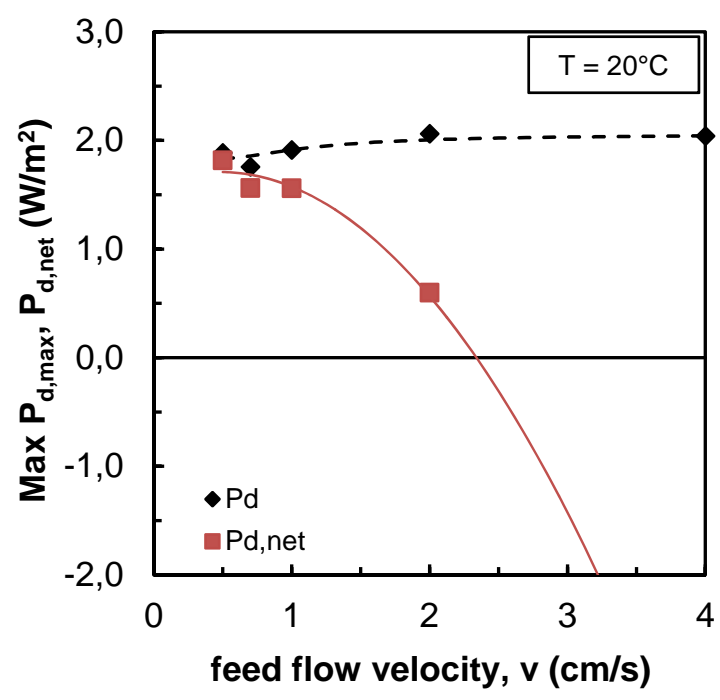

a)

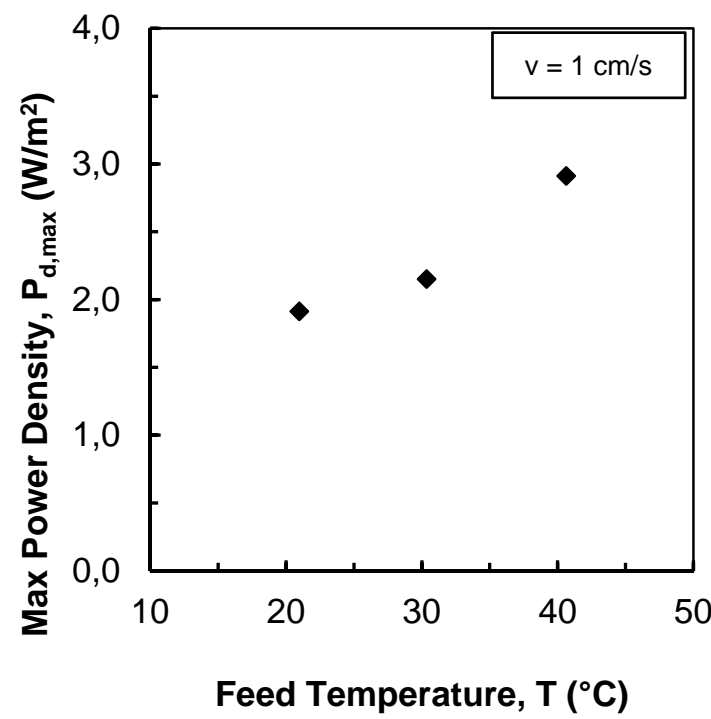

b)

Figure 1. Dependences of max Power density on the fluid linear velocity (a) and on the average feed solutions temperature (b), measured in a 50 cell pairs stack equipped with Fujifilm membranes, Deukum $270 \mu \mathrm{m}$ spacers, and fed with $0.5 \mathrm{M} \mathrm{NaCl}$ and $5 \mathrm{M} \mathrm{NaCl}$ feed solution [14].

The dependence on feed concentration is reported in paragraph 2.4.2 and in Figure 4, where experimental data has been adopted for model calibration. Interestingly, they indicate a dramatic potential increase in power density output when reducing the diluate compartment concentration to a value typical of brackish water, achieving in this way Pd values of almost to $5 \mathrm{~W} / \mathrm{m}^{2}$ of cell pair.

When testing the system under the experimental conditions maximising the power output (as reported in Table 1), a considerably high value of power density has been achieved. Such result is even more impressing looking 
at the value of the corrected power density, i.e. the power density theoretically achievable if the electrode compartments resistance were null [14], which is up to almost $7 \mathrm{~W} / \mathrm{m}^{2}$ of cell pair.

Table 1. Power density measurements at "optimal" operating conditions".

\begin{tabular}{|c|c|c|c|c|c|}
\hline $\begin{array}{c}\text { Diluate } \\
\text { concentration, } \\
\mathrm{C}_{\text {LOW }} \\
(\mathrm{mol} / \mathrm{l})\end{array}$ & $\begin{array}{c}\text { Concentrate } \\
\text { concentration, } \\
\text { CHIGH }_{\text {Hol/l) }}\end{array}$ & $\begin{array}{c}\text { Feed } \\
\text { temperature, } \\
\mathbf{T} \\
\left({ }^{\circ} \mathrm{C}\right)\end{array}$ & $\begin{array}{c}\text { Max Power } \\
\text { Density, } \\
\text { Pd,max }_{\text {d }} \\
\left(\mathbf{W} / \mathbf{m}^{2}\right)\end{array}$ & $\begin{array}{c}\text { Net Power } \\
\text { Density }^{(a)} \text {, } \\
\text { Pd,net }_{\text {d,n }} \\
\left(\mathrm{W} / \mathbf{m}^{2}\right)\end{array}$ & $\begin{array}{c}\text { Corrected Power } \\
\text { Density }^{(\mathbf{b})}, \\
\text { P }_{\text {d,corr }} \\
\left(\mathbf{W} / \mathbf{m}^{2}\right)\end{array}$ \\
\hline 0.1 & 5.0 & 40.4 & 6.01 & 5.65 & 6.82 \\
\hline
\end{tabular}

Finally, looking at the net power density output in Table 1, i.e. the net power density obtained after subtracting the pumping power losses related to the stack pressure drops, it is worth noting how this achieves a value of almost $6 \mathrm{~W} / \mathrm{m}^{2}$, indicating a significantly high value of actual power density obtained from the system under investigation.

\subsection{CFD Modelling and Process simulation}

In parallel with the experimental activities, a detailed modelling work has been carried out in order to give directions for optimal design of the SGP-RE system. In particular, a multi-scale modelling approach was adopted, being able to perform the optimisation of stack geometry and operating conditions, as well as give a reliable sensitivity analysis of the process.

The use of a multi-scale approach is particularly useful for such a complex process optimisation case. It allowed to study the system at different levels of description, starting from a detailed analysis of the fluid dynamics inside channels, up to a macroscopic description of the SGP-RE unit. For this reason, two modelling tools were identified as suitable to reach the aforementioned goals: a Computational Fluid Dynamics (CFD) commercial code (Ansys CFX $\left.{ }^{\circledR} 13\right)$, coupled with an equation-based process simulator (PSE gPROMS ${ }^{\circledR}$ ).

\subsubsection{CFD modelling of the spacer-filled channels}

A Computational Fluid Dynamics (CFD) model was adopted to investigate the fluid flow behaviour inside the spacer-filled channels, providing information in terms of pressure drops along the channels and mass transport through the membranes. The aim of this modelling activity was to identify the suitable conditions for the solutions compartments, both in terms of spacer thickness/geometry and feed flow rates. With this regard, CFD simulations were performed along with experimental characterisation of five different commercial spacers, investigating the influence of thickness and geometry on fluid dynamics [16-19].

The CFD analysis was carried out by different approaches focused on a finely discretised repeating unit computational domain or a coarser domain representing a larger portion of the spacer filled channel. Several different spacer geometries were investigated with woven and non-woven filaments and different channel thicknesses, though only the case of a woven spacer supplied by Deukum GmbH is presented here (Figure 2). Using the unit cell approach, translational periodic boundary conditions were imposed to velocities on the surfaces perpendicular to the fluid flow direction (Z-axis in Figure 2) and on the lateral surfaces perpendicular to the $\mathrm{X}$-axis. 


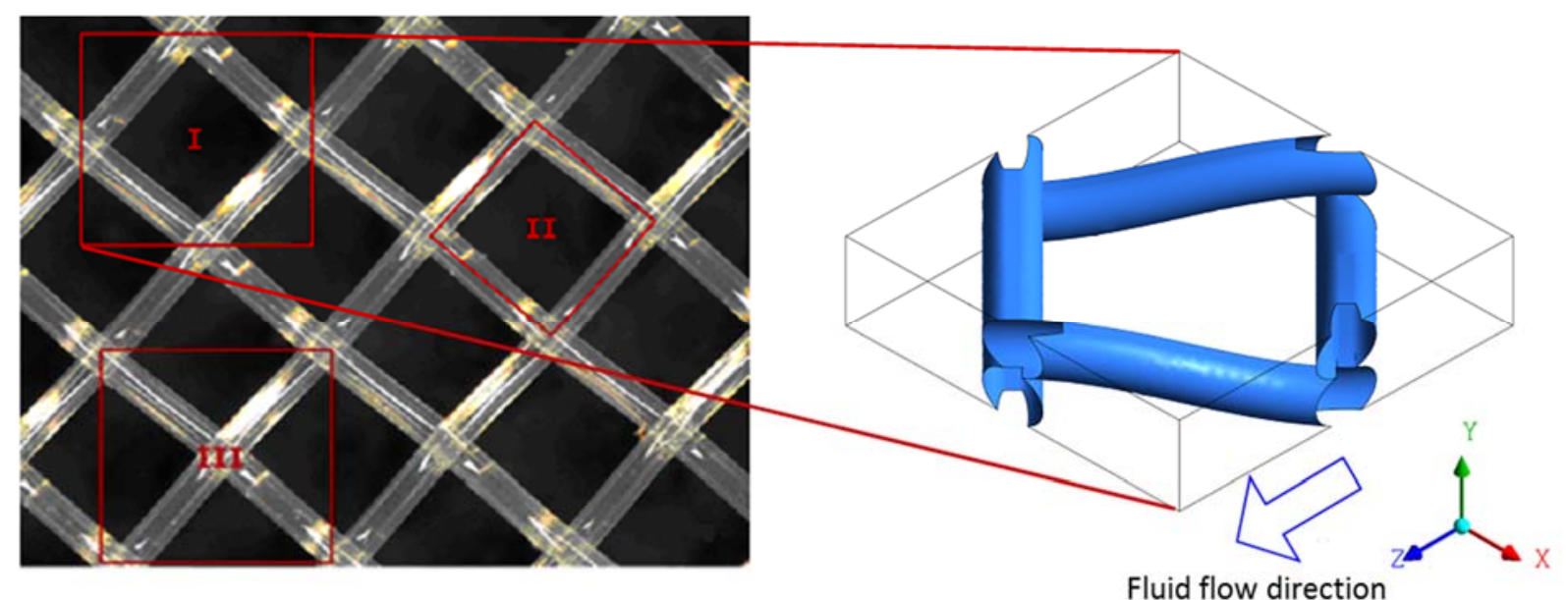

Figure 2. Different types of repeating Unit Cell for a woven spacer [18]. The case I has been chosen for the present investigation.

The filaments surfaces and the surfaces perpendicular to the Y-axis (membrane surfaces) were defined as walls and no-slip boundary conditions were imposed on them.

CFD modelling allowed also the characterisation of mass transport phenomena within the spacer-filled channel. In particular, the aim of this study was investigating the influence of concentration polarization phenomena on process performance. With this regard, CFD simulations were performed for a $280 \mu \mathrm{m}$ polyamide commercial woven spacer (Deukum GmbH, Germany) under different conditions of current density and flow velocity. The CFD model was able to predict the fluid flow behaviour of both seawater and brine, taking into account the effect of salt concentration on transport properties of the solutions. Polarization coefficients were defined to quantify the effect of polarization phenomena inside channels:

$$
\vartheta_{b}=\frac{C_{b}^{\text {int }}}{C_{b}^{\text {bulk }}} \quad \vartheta_{s}=\frac{C_{s}^{\text {bulk }}}{C_{s}^{\text {int }}}
$$

where subscripts $b$ and $s$ refer to brine and seawater, while superscripts int and bulk refer to membrane-solution interface and bulk conditions, respectively. These coefficients can be seen as a measure of the effect of polarization phenomena on the available driving force for the SGP-RE process (note that both $\vartheta_{b}$ and $\vartheta_{s}$ are defined to be always $\leq 1$ ). Model results are shown in Figure 3, where concentration polarization coefficients are plot as a function of current density and flow velocity. 

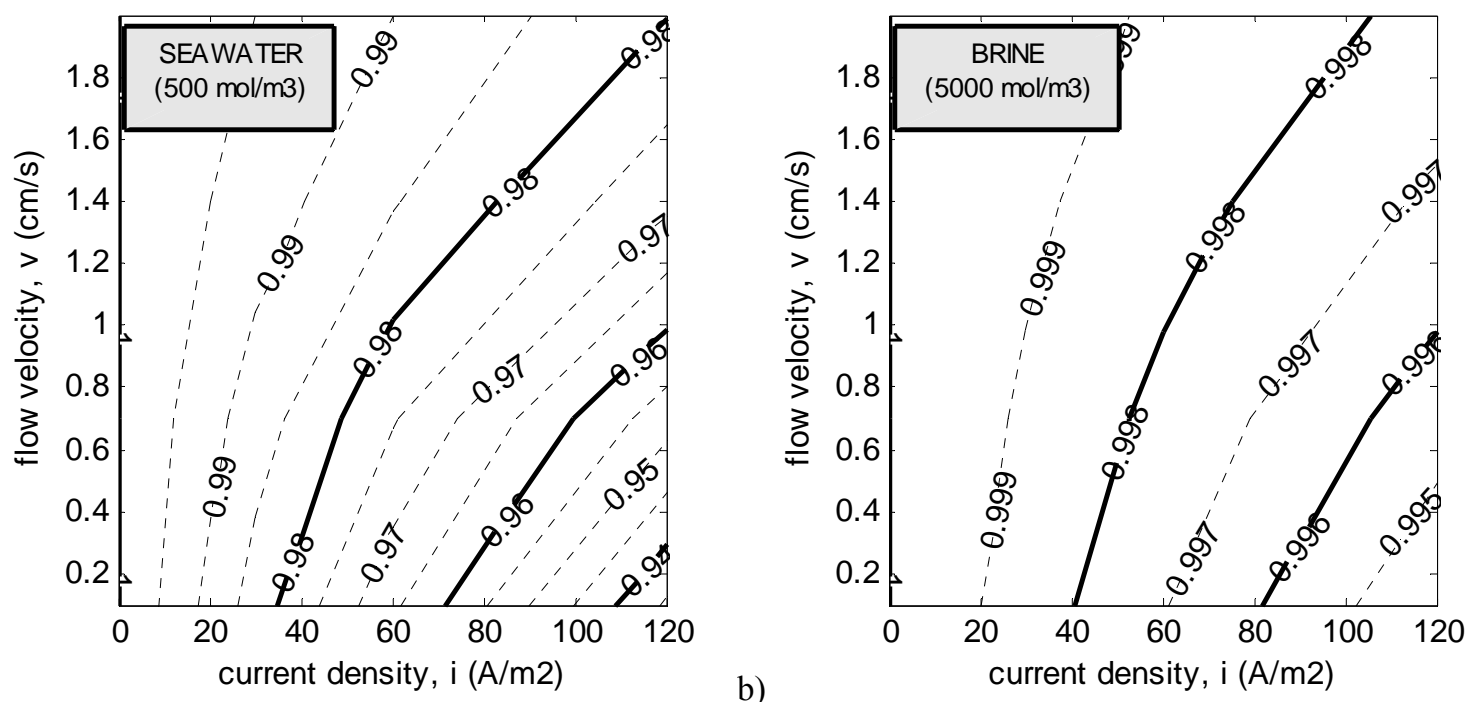

Figure 3. Effect of current density and fluid velocity on polarization coefficients. Case a) Seawater $(0.5 \mathrm{M} \mathrm{NaCl})$; case b) Brine $(5 \mathrm{M} \mathrm{NaCl})$. Model predictions from CFD simulations with $280 \mu \mathrm{m}$ polyamide woven spacer (Deukum GmbH, Germany) [20, 21].

Interestingly, model predictions show that the polarization phenomena are more relevant for seawater, while the effect is rather negligible for brine. This is due to the high concentration in the bulk, which makes negligible the concentration reduction in the diffusion boundary layer.

\subsubsection{Development and validation of a process simulator}

A comprehensive model was developed focusing on two different levels of description for the SGP-RE process:

- a low-hierarchy scale, predicting the physical phenomena inside the repeating unit of the SGP-RE system (cell pair);

- a high-hierarchy scale, developed for the entire equipment (stack), describing the interaction among all cell pairs and providing information of the overall performance of the equipment.

The model is based on mass balance and transport equations through compartments and membranes, constitutive equations for physical properties of solutions and for describing the ohmic and non-ohmic phenomena controlling electrical variables inside the stack. A number of non-ideal effects are taken into account in order to simulate more realistically the stack behaviour, such as the water transport through membranes (both osmotic and electro-osmotic fluxes), co-ions transport (due to non-ideal membrane permselectivity), and the parasitic currents (i.e. ionic currents not through membranes but along stack manifolds). The proposed model was implemented in a process simulator (gPROMS Model Builder, PSE) and validated using experimental data collected with the lab-scale stack. Results of the model validation are shown in Figure 4, where the achievable power density is plotted under different diluate (LOW) and concentrate (HIGH) concentration. 

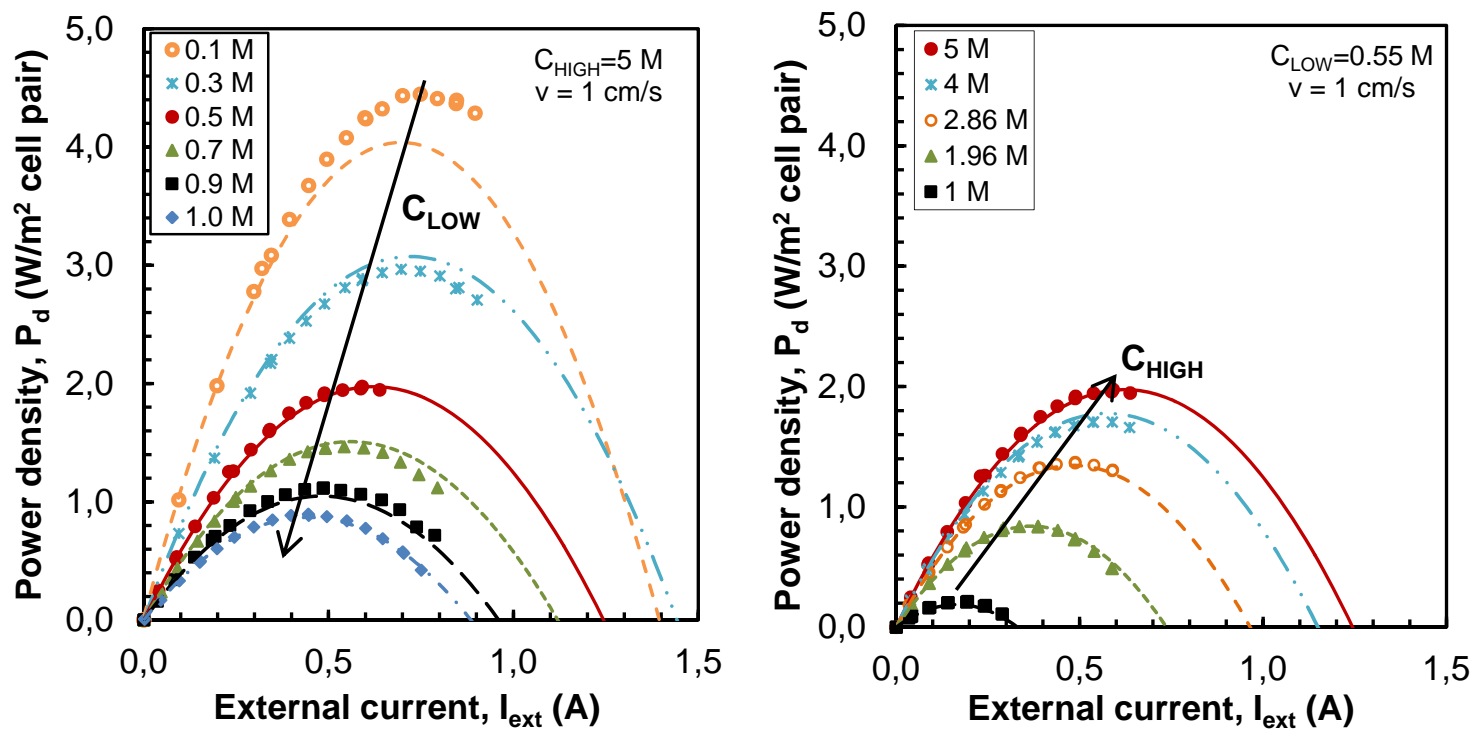

Figure 4. Effect of the inlet concentration on power density. Experimental (points) and simulated (lines) data for a 50-cells stack equipped with Fujifilm membranes, Deukum $270 \mu \mathrm{m}$ spacers. Feed flow velocity: $1 \mathrm{~cm} / \mathrm{s} ; \mathrm{T}=20^{\circ} \mathrm{C}$. Left: changing diluate $(\mathrm{LOW})$ concentration $\left(\mathrm{C}_{\mathrm{HIGH}}=5 \mathrm{M}\right)$. Right: changing concentrate $(\mathrm{HIGH})$ concentration $\left(\mathrm{C}_{\mathrm{LOW}}=0.55 \mathrm{M}\right)[22]$.

The model can predict with reasonable accuracy the experimental behaviour in a wide range of salt concentration, though it slightly underestimate the maximum power density for low diluate concentration, thus being conservatively predicting the behaviour of the system. As a result, it can be used as a safe predictive modelling tool to simulate the process performance under different operating conditions.

A complete process simulator was built for the SGP-RE plant, taking into account all inlet/outlet streams properties, as well as feed pumps and electrical connection with an external load (Figure 5). In this way, the simulator allows the user to define geometrical parameters, as well as operating conditions (flow rates, salt concentration, feed temperature) so as to simulate the process performance under several possible scenarios.

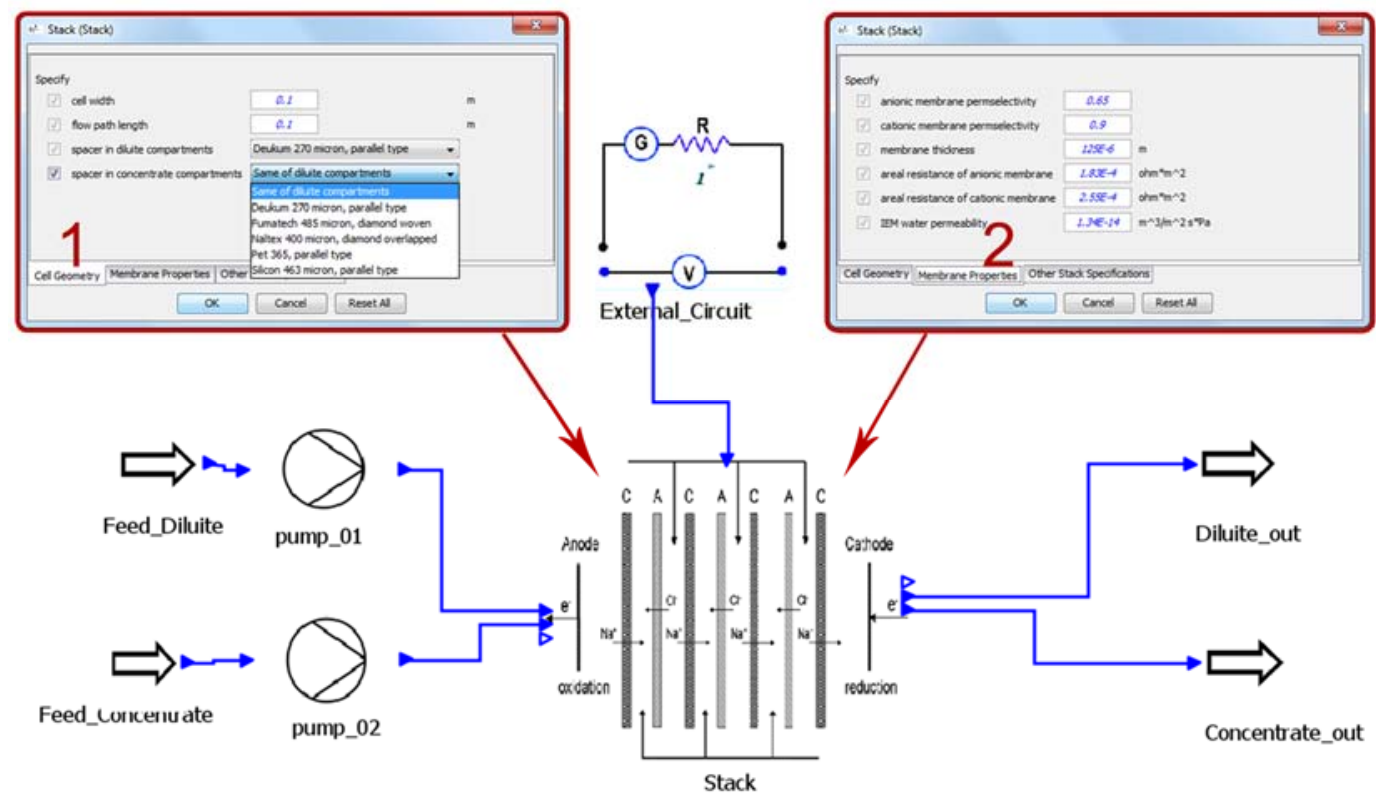

Figure 5. Graphical User Interface (GUI) of the developed process simulator on gPROMS 3.6. Two dialog boxes for the stack specifications are shown as example. 
Finally, the model was adopted to investigate the best operating conditions for the SGP-RE process. For instance, the influence of salt concentration on power density was analysed. Figure 6 shows a distribution map of the achievable power density using different salt concentration as feed solutions, spacing from river water $(0.01 \mathrm{M})$ to seawater $(0.5 \mathrm{M})$ as diluate, and from seawater $(0.5 \mathrm{M})$ to brine $(5 \mathrm{M})$ as concentrate.

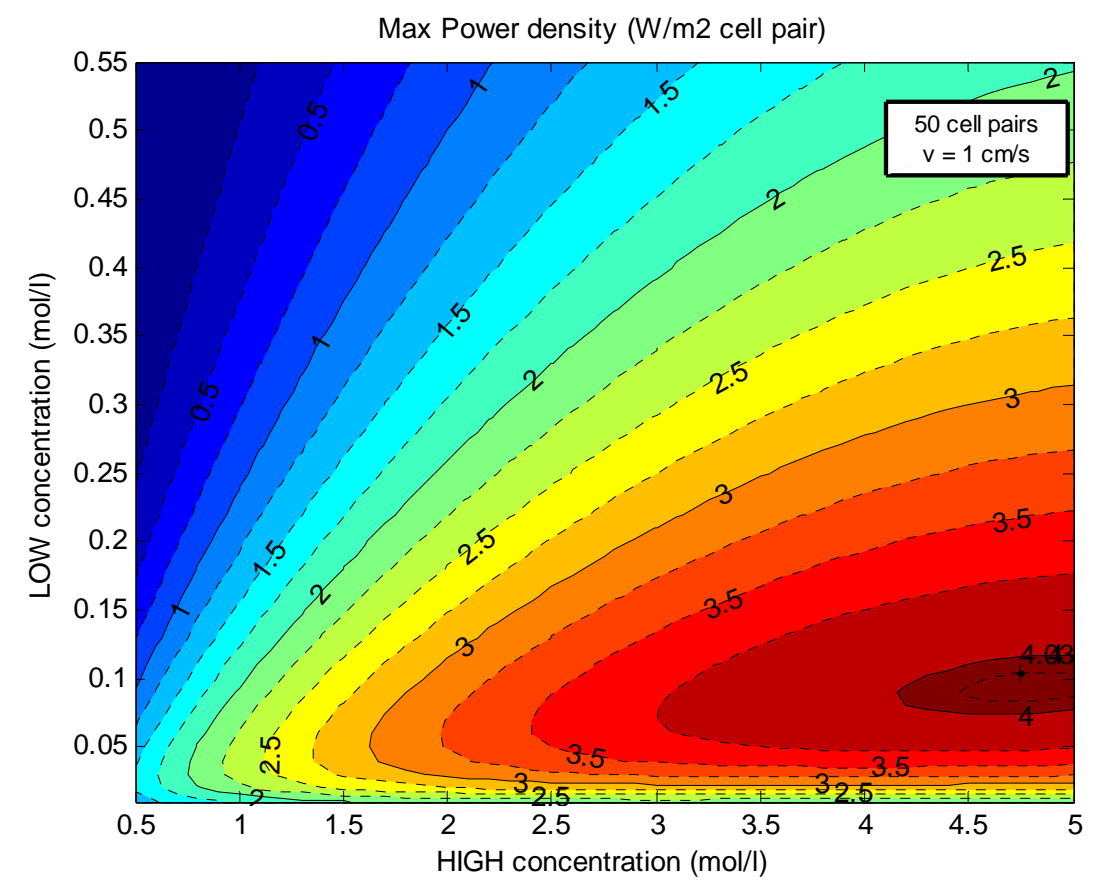

Figure 6. Effect of LOW/HIGH inlet concentration on maximum power density. Simulations of a 50-cells stack equipped with Fujifilm membranes, Deukum $270 \mu \mathrm{m}$ spacers; feed flow velocity inside channels: $1 \mathrm{~cm} / \mathrm{s} . \mathrm{T}=20^{\circ} \mathrm{C}$. Contours show max power density values [22].

It is worth noting that a diluate concentration lower than $0.05 \mathrm{M} \mathrm{NaCl}$ is unsuitable for maximising the power density due to the high ohmic resistance of the diluate compartment. Interestingly, the highest power density can be achieved using a $70-90 \mathrm{mM} \mathrm{NaCl}$ solution as diluate, which is a typical concentration for brackish water, together with a $4.5-5 \mathrm{M} \mathrm{NaCl}$ solution as concentrate. In this way, a power density higher than $4 \mathrm{~W} / \mathrm{m}^{2}$ of cell pair is conservatively predicted by the model, and can be increased or a further $30 \%$ if the feed temperature rises from $20^{\circ} \mathrm{C}$ up to $40^{\circ} \mathrm{C}[22]$.

\section{Conclusions}

The aim of the REAPower project is the power production through a reverse electrodialysis system fed by seawater and concentrated brine as feed solutions. During the first 3-years period of the project significant achievements have been reached in $R \& D$ for this technology. The development of new ion exchange membranes by Fujifilm allowed to reach high permselectivity values in concentrated solutions $(65 \%$ for AEM, $90 \%$ for CEM) and to lower the IEM resistance. An innovative cross-flow stack was designed and constructed by REDstack to enhance flow distribution and power production. This stack was afterwards widely tested on a labscale setup, achieving for the first time in the literature power density values between 6 and $7 \mathrm{~W} / \mathrm{m}^{2}$ of cell pair using brackish water and brine as feed solutions. Modelling activities, performed by means of a CFD code coupled with an equation-based process simulator allowed the simulation and prediction of fluid dynamics and overall performance of the SGP-RE system. These results provided useful information for the final goal of the project, i.e. the construction of the first SGP-RE system on a small pilot-scale, in order to demonstrate the feasibility of the future scale-up for this technology. 


\section{Acknowledgements}

This work has been performed within the REAPower (Reverse Electrodialysis Alternative Power production) project [7], funded by the EU-FP7 programme (Project Number: 256736) within the Future Emerging Technologies topic.

\section{References}

[1] R. E. Lacey, "Energy by reverse electrodialysis," Ocean Engineering, vol. 7, pp. 1-47, 1980.

[2] R. E. Pattle, "Production of Electric Power by mixing Fresh and Salt Water in the Hydroelectric Pile," Nature, vol. 174, pp. 660-660, 1954.

[3] J. W. Post, J. Veerman, H. V. M. Hamelers, G. J. W. Euverink, S. J. Metz, K. Nymeijer, et al., "Salinity-gradient power: Evaluation of pressure-retarded osmosis and reverse electrodialysis," Journal of Membrane Science, vol. 288, pp. 218-230, 2007.

[4] D. Brogioli, "Extracting renewable energy from a salinity difference using a capacitor," Physical review letters, vol. 103, p. 058501(4), 2009.

[5] G. Z. Ramon, "Membrane-based production of salinity-gradient power," Energy \& environmental science, vol. 4, pp. 4423-4434, 2011.

[6] A. Cipollina, A. Misseri, G. D. Staiti, A. Galia, G. Micale, and O. Scialdone, "Integrated production of fresh water, sea salt and magnesium from sea water," Desalination and Water Treatment, vol. 49, pp. 390-403, 2012.

[7] www.reapower.eu. Copyright 2010 REAPower/WIP Munich.

[8] M. Tedesco, A. Cipollina, A. Tamburini, W. van Baak, and G. Micale, "Modelling the Reverse ElectroDialysis process with seawater and concentrated brines," Desalination and Water Treatment, vol. 49, pp. 404-424, 2012.

[9] K. Kontturi, L. Murtomäki, and J. A. Manzanares, Ionic Transport Processes: In Electrochemistry and Membrane Science: OUP Oxford, 2008.

[10] O. Scialdone, C. Guarisco, S. Grispo, A. D. Angelo, and A. Galia, "Investigation of electrode material Redox couple systems for reverse electrodialysis processes. Part I: Iron redox couples," Journal of Electroanalytical Chemistry, vol. 681, pp. 66-75, 2012.

[11] O. Scialdone, C. Guarisco, S. Grispo, A. D. Angelo, and A. Galia, "Investigation of electrode material Redox couple systems for reverse electrodialysis processes. Part II: Experiments in a stack with 10-50 cell pairs," Journal of Electroanalytical Chemistry, vol. 704, pp. 1-9, 2013.

[12] J. Veerman, M. Saakes, S. J. Metz, and G. J. Harmsen, "Reverse electrodialysis: Evaluation of suitable electrode systems," Journal of Applied Electrochemistry, vol. 40, pp. 1461-1474, 2010.

[13] O. S. Burheim, F. Seland, J. G. Pharoah, and S. Kjelstrup, "Improved electrode systems for reverse electro-dialysis and electro-dialysis," Desalination, vol. 285, pp. 147-152, 2012.

[14] J. Helsen, A. Cipollina, P. Modica, G. Micale, and E. Brauns, "Seawater and concentrated brine for Reverse Electrodialysis power production: experimental investigation on process performances and perspectives," in preparation, 2013.

[15] J. Helsen, P. Modica, and A. Cipollina, "Lab-scale SGP-RE stack testing: Small scale lab stack test results," REAPower project internal report, 2013.

[16] L. Gurreri, A. Tamburini, A. Cipollina, and G. Micale, "CFD analysis of the fluid flow behavior in a reverse electrodialysis stack," Desalination and Water Treatment, vol. 48, pp. 390-403, 2012.

[17] L. Gurreri, A. Tamburini, A. Cipollina, G. Micale, and M. Ciofalo, "CFD simulation of mass transfer phenomena in spacer filled channels for reverse electrodialysis applications," Chemical Engineering Transactions, vol. 32, pp. 1879-1884, 2013.

[18] A. Tamburini, G. La Barbera, A. Cipollina, M. Ciofalo, and G. Micale, "CFD simulation of channels for direct and reverse electrodialysis," Desalination and Water Treatment, vol. 48, pp. 370-389, 2012.

[19] L. Gurreri, A. Tamburini, A. Cipollina, G. Micale, and M. Ciofalo, "CFD prediction of concentration polarization phenomena in spacer-filled channels for reverse electrodialysis," in preparation, 2013.

[20] L. Gurreri, A. Tamburini, A. Cipollina, G. Micale, and M. Ciofalo, "CFD Simulation of Mass Transfer Phenomena in Spacer-filled Channels," Chemical Engineering Transactions, 2013.

[21] G. Micale, A. Cipollina, A. Tamburini, and L. Gurreri, "Report on the CFD analysis of the effects of spacer filled channel geometry on the system performance," REAPower project internal report, 2012.

[22] M. Tedesco, A. Cipollina, A. Tamburini, I. D. L. Bogle, and G. Micale, "Reverse Electrodialysis process with seawater and concentrated brines: a comprehensive model for equipment design," submitted for publication, 2013. 